\title{
Door-to-door survey of major neurological disorders (project) in Al Quseir City, Red Sea Governorate, Egypt
}

This article was published in the following Dove Press journal:

Neuropsychiatric Disease and Treatment

25 May 2013

Number of times this article has been viewed

\author{
Hamdy NA El Tallawy' \\ Wafaa MA Farghaly' \\ Tarek A Rageh' \\ Ghaydaa A Shehata' \\ Reda Badry' \\ Nabil A Metwally2 \\ Esam A El Moselhy² \\ Mahmoud Hassan ${ }^{2}$ \\ Mohamed A Sayed ${ }^{3}$ \\ Ahmed A Waris' \\ Yaser Hamed ${ }^{2}$ \\ Islam Shaaban ${ }^{2}$ \\ Mohamed A Hamed' \\ Mahmoud Raafat Kandil' \\ 'Department of Neurology, Faculty \\ of Medicine, Assiut University, Assiut, \\ Egypt; ${ }^{2}$ Department of Neurology and \\ Public Health, Faculty of Medicine, \\ Al-Azhar University (Assiut branch), \\ Assiut, Egypt; ${ }^{3}$ Department of \\ Neurology, Faculty of Medicine, Sohag \\ University, Sohag, Egypt
}

\begin{abstract}
A door-to-door survey, including every household, was conducted for all inhabitants of Al Quseir City (33,283), Red Sea Governorate, Egypt by three specialists of neurology as well as nine senior staff members of neurology and 15 female social workers to assess the epidemiology of major neurological disorders. Over six phases, from July 1, 2009 to January 31, 2012, screening of all eligible people in the population was carried out, by which case ascertainment of all major neurological disorders included in the study was done according to the accepted definitions and diagnostic criteria of the World Health Organization. The order of frequency of prevalence of the studied neurological disorders was dementia (3.83\% for those aged $>60$ years), migraine $(2.8 \%$ for those aged $>8$ years), stroke (6.2/1000 for those aged $>20$ years), epilepsy (5.5/1000), Parkinson's disease (452.1/100,000 for those aged $>40$ years), cerebral palsy (3.6/1000 among children $<18$ years), spinal cord disorders $(63 / 100,000)$ dystonia $(39.11 / 100,000)$, cerebellar ataxia $(30.01 / 100,000)$, trigeminal neuralgia $(28 / 100,000$ for those aged $>37$ years $)$, chorea $(21.03 / 100,000)$, athetosis $(15 / 100,000)$, and multiple sclerosis $(13.74 / 100,000)$. The incidence rates of stroke, epilepsy, and Bell's palsy were 181/100,000, 48/100,000, and 98.9/100,000 per year, respectively.
\end{abstract}

Keywords: prevalence, incidence, neurological disorders

\section{Introduction}

Over the last 3 decades, population-based studies aiming to determine the true burden of neurological disorders have increasingly been acknowledged. Nevertheless, in developing countries, the limited access of neurologists to rural areas and the logistic and economic limitations to perform neuroepidemiological studies have significantly complicated their implementation. ${ }^{1}$

However, a series of epidemiological studies was conducted in upper Egypt in the last 2 decades. Epidemiologic research has progressed in Egypt, particularly over the last 6 years, through two major projects to evaluate the incidence and prevalence of different neurological disorders in Al Kharga district, New Valley and Al Quseir City, Red Sea Governorate, Upper Egypt.

This project aimed to evaluate the incidence and prevalence of epilepsy and stroke; the incidence of Bell's palsy; and the prevalence of dementia, chorea, athetosis, dystonia, Parkinson's disease, cerebellar ataxia, multiple sclerosis, migraine, trigeminal neuralgia, cerebral palsy, and spinal cord disorders.

\section{Methods}

\section{Study area}

The project was designed to assess major neurological disorders in Al Quseir City as a representative coastal city lying on the Red Sea. Al Quseir City 
has a long history, dating from the pharaonic era when it was named Thagho. At the time of the Batlamic and Romanic eras it was named Leukos Limen and Poptus Albus, respectively. Its population is representative of native inhabitants and immigrants from different governorates who reside there to participate in tourist activities, fishing, and mining. ${ }^{2}$

All eligible inhabitants who had been living in Al Quseir City for at least 6 months at the time of the interview were included in the survey. The study duration extended from July 1, 2009 to June 31, 2012 through different stages of data collection, a preparatory stage, screening, data entry, statistical manipulation, and tabulation.

All households ( $\mathrm{n}=33,285 ; 7497$ families) and both sexes, with $49.4 \%$ males $(n=16,428)$ and $50.6 \%$ females ( $\mathrm{n}=16,857)$, were screened by three neurologists, in addition to 15 female social workers (for sociodemographic data collection) via a door-to-door survey. A standardized questionnaire, the sensitivity and specificity of which are $96 \%$ and $93.2 \%$, respectively, ${ }^{3}$ was applied by three neurologists to every member of each family (children and elderly were questioned through their caregivers). A total population of $31,754(95.4 \%)$ were free from any neurological disorder, versus $1531(4.6 \%)$ of both sexes $(3.9 \%[n=647]$ males and $5.2 \%$ [ $\mathrm{n}=884]$ females) had different neurological disorders.

Full history data and examinations (general, systemic, and neurological) were carried out by the three neurologists in collaboration with nine other senior staff members from neurology departments in Assiut, Al-Azhar, Sohag, and Qena Universities.

All neurological disorders were finally diagnosed after evaluation by the three neurologists, each separately, as well as specific investigatory tools. Diagnoses of different neurological disorders were based on the accepted definition and diagnostic criteria given by the World Health Organization., ${ }^{4,5}$ The definition of incidence rate, prevalence, and lifetime prevalence in this study are according to those provided by Abramson. ${ }^{6}$

\section{Ethics}

Ethical approval for the study was obtained from the Research Ethics Committee of Assiut University and from the Ministry of Health to carry out this project in Al Quseir City, Red Sea Governorate. Each participant provided written informed consent (children, illiterate, and disabled individuals consented through the responsible person in the family or their caregivers).

\section{Statistical analysis}

Data management was carried out by two specialists in data entry and three medical statisticians using SPSS software (v 16; IBM Corporation, Armonk, NY, USA), Excel (Microsoft Corporation, Redmond, WA, USA), and EpiCalc 2000 (Microsoft Corporation).

\section{Results}

The incidence rates of epilepsy, stroke, and Bell's palsy compared to worldwide rates are illustrated in Table 1. The prevalence of the neurological disorders studied in Al Quseir City is illustrated in Tables 2-4. Table 5 shows a record of the prevalence of different neurological disorders studied in Al Quseir City and worldwide.

\section{Discussion}

The increase in the number of different major projects to study neurological disorders worldwide during the last 3 decades will help all of us to construct a map of neurological disorders throughout the world and clarify the burden of neurological disorder among different countries.

This study is a new one in the series of large epidemiological studies carried out in our country to assess the burden of neurological disorders at different localities in Egypt. Screening was carried out through a door-to-door survey, including every household, by using a standardized questionnaire, ${ }^{7}$ with subsequent clinical evaluation of all suspected cases by neurologists (three specialists as well as nine senior staff members) in $\mathrm{Al}$ Quseir General Hospital and Assiut University Hospital.

Table I Incidence rates of epilepsy, stroke, and Bell's palsy in AI Quseir City, Red Sea Governorate, Egypt

\begin{tabular}{|c|c|c|}
\hline & $\begin{array}{l}\text { Incidence rate } \\
\text { (per } 100,000 \\
\text { per year) }\end{array}$ & $\begin{array}{l}\text { Previously reported worldwide } \\
\text { incidence rates (per } 100,000 \\
\text { per year) }\end{array}$ \\
\hline Epilepsy & $\begin{array}{l}48.0 \\
(n=33,285)\end{array}$ & $\begin{array}{l}43.14 \text { in Al Kharga District, Egypt } \\
43.4 \text { in Ferrara, Italy } \\
63-158 \text { in sub-Saharan Africa } \\
81.1 \text { in Northern Tanzania }{ }^{7} \\
16 \text { in New York, NY, USA } \\
47 \text { in England } \\
29 \text { in The Netherlands }\end{array}$ \\
\hline Stroke & $\begin{array}{l}|8| \\
(\geq 20 \text { years old; } \\
n=19,848)\end{array}$ & $\begin{array}{l}250 \text { in Al Kharga District, Egypt }{ }^{10} \\
18.0 \text { in Sohag, Egypt }{ }^{22} \\
240 \text { in France }{ }^{14}\end{array}$ \\
\hline Bell's Palsy & $\begin{array}{l}98.9 \\
(\geq 9 \text { years old; } \\
n=27,282)\end{array}$ & $\begin{array}{l}51.89 \text { in Al Kharga District Egypt } \\
(\geq 8 \text { years old })^{10} \\
\text { I3-34 in USA }{ }^{16} \\
52.8 \text { (> I5 years old) in Sicily, Italy } \\
(1984-1987)^{17} \\
20.2 \text { in the UK }(1992-1996)^{18}\end{array}$ \\
\hline
\end{tabular}


Table 2 Prevalence per 1000 of cerebral palsy, stroke, and epilepsy in Al Quseir City, Red Sea Governorate, Egypt

\begin{tabular}{llll}
\hline $\begin{array}{l}\text { Neurological } \\
\text { disorder }\end{array}$ & Age of patients & $\mathbf{n}$ & $\begin{array}{l}\text { Prevalence } \\
\text { per 1000 }\end{array}$ \\
\hline Epilepsy & All ages & 33,285 & 5.5 \\
Stroke* & $\geq 20$ years & 19,848 & 6.2 \\
Cerebral palsy & $<18$ years & 12,093 & 3.6 \\
\hline
\end{tabular}

Note: *One case, aged $<20$ years, is not shown in the table.

The limitations of this study include:

- The stigma of some neurological disorders (eg, the view of epilepsy as an "evil" attack and dementia as a normal aging process) necessitates extraneous effort from the project team to clarify the nature of these disorders and their suitability to treat.

- Noncompliance by the patients with the prescribed treatments due to scarce financial resources and lack of health care systems suited for long term needs of chronic neurological disorders.

These limitations required an extra effort on the project team to encourage participation of most inhabitants through:

- Detailed explanations of the project goals by the members of the project team and responsible authorities in the defined area of the study.

- Recruitment of well-known key persons, as well as female social workers, among native inhabitants, who accompanied the screening team to facilitate family interviews and encourage participation.

- A capture-recapture method for those who were not present at their homes during the first visit, whereby they were visited again.

The incidence rate of epilepsy $(48 / 100,000$ per year) in $\mathrm{Al}$ Quseir City is within the international rate ${ }^{7-9}$ and lower than that recorded in sub-Saharan Africa ${ }^{10}$ and Northern Tanzania. ${ }^{11}$ Meanwhile, the incidence rate of epilepsy $(48 / 100,000)$ in this

Table 3 Prevalence per 100 of dementia and migraine in Al Quseir City, Red Sea Governorate, Egypt

\begin{tabular}{lll}
\hline Age of patients & $\mathbf{n}$ & Prevalence per $\mathbf{~ 0 0}$ \\
\hline Dementia & & \\
$\geq 50$ years & 4663 & 2.01 \\
$\geq 60$ years & 2113 & 3.83 \\
$\geq 70$ years & 692 & 8.12 \\
$\geq 80$ years & 158 & 13.5 \\
Migraine* & & \\
$\geq 8$ years & 27,804 & 2.8 \\
\hline
\end{tabular}

Note: *No recorded cases of migraine in those aged $<8$ years.
Table 4 Prevalence of extrapyramidal syndromes, cerebellar ataxia, trigeminal neuralgia, multiple sclerosis, and spinal cord injury per 100,000 population

\begin{tabular}{llll}
\hline $\begin{array}{l}\text { Neurological } \\
\text { disorder }\end{array}$ & $\begin{array}{l}\text { Age of } \\
\text { patients }\end{array}$ & $\mathbf{n}$ & $\begin{array}{l}\text { Prevalence } \\
\text { per 100,000 }\end{array}$ \\
\hline $\begin{array}{llll}\text { Extrapyramidal syndromes } \\
\text { Parkinson's disease }\end{array}$ & $\geq 40$ years & 8183 & 452.1 \\
$\quad$ Chorea & All ages & 33,285 & 21.03 \\
Dystonia & All ages & 33,285 & 39.1 \\
$\quad$ Athetosis & All ages & 33,285 & 15.0 \\
Cerebellar ataxia & All ages & 33,285 & 30.0 \\
Trigeminal neuralgia & $\geq 37$ years & 9142 & 28.0 \\
Multiple sclerosis & $\geq 17$ years & 21,774 & 13.74 \\
Spinal cord surgery & All ages & 33,285 & 63.0 \\
\hline
\end{tabular}

study was higher than that recorded in New York, NY, USA $(16 / 100,000)^{12}$ and in The Netherlands $(29 / 100,000) .{ }^{13}$

Although the incidence rate of stroke in Al Quseir City was lower than that recorded in France ${ }^{14}$ and other areas of Egypt (Al Kharga district, New Valley), ${ }^{7}$ it is similar to that recorded in Sohag, Upper Egypt. ${ }^{15}$

The incidence rate of Bell's palsy in Al Quseir City was higher than that recorded worldwide. ${ }^{7,16-18}$

The great variation in the incidence rate of epilepsy, stroke, and Bell's palsy in $\mathrm{Al}$ Quseir City in comparison to incidence rates worldwide could be attributed to the different genetic characteristics of the population in Al Quseir City, where the population contains a mixture of native inhabitants and immigrants from different adjacent governorates, and thus a variable (not distinct) genetic predisposition for various neurological disorders.

Study of age-specific prevalence of some neurological disorders in Al Quseir City revealed that dementia ( $3.83 \%$ of those aged $\geq 60$ years) was the most frequent, followed by migraine $(2.8 \%)$, stroke (6.2/1000), epilepsy (5.5/1000), Parkinson's disease $(452.1 / 100,000)$, and cerebral palsy (3.6/1000). However, less frequent neurological disorders were spinal cord injury $(63.0 / 100,000)$, dystonia $(39.1 / 100,000)$, cerebellar ataxia $(30.0 / 100,000)$, trigeminal neuralgia $(28 / 100,000)$, chorea $(21.0 / 100,000)$, athetosis $(15.0 / 100,000)$, and multiple sclerosis $(13.7 / 100,000)$.

MacDonald et al's UK study found that stroke was the most frequent neurological disorder, followed by epilepsy, then Parkinson's disease, and, finally, multiple sclerosis. ${ }^{9}$ On the other hand, in a Mexican rural community in 2011, Quet et al found that headache was the most frequent neurological disorder, followed by epilepsy, stroke, Parkinson's disease, and cerebellar ataxia. ${ }^{19}$ 
Table 5 Prevalence of different neurological disorders worldwide per 100,000

\begin{tabular}{|c|c|c|c|c|c|c|c|c|c|c|c|c|c|}
\hline Study & D & $\mathbf{M}$ & $\mathbf{S}$ & $\mathbf{E}$ & $\mathbf{P}$ & $\mathbf{C P}$ & DY & CA & $\mathbf{T N}$ & C & $\mathbf{A}$ & MS & SCD \\
\hline Present study (Al Quseir, Egypt) & 3830 & 2800 & 620 & 550 & 452.1 & 360 & 39.1 & 30 & 28 & 21.03 & 15 & 13.74 & 63 \\
\hline El Tallawy et al (Al Kharga, Egypt) ${ }^{7}$ & 4450 & - & 560 & 698 & 213.15 & 203 & 30.36 & 38 & - & 31.96 & 1.6 & - & - \\
\hline \multirow[t]{2}{*}{ MacDonald et al $(\mathrm{UK})^{10}$} & - & - & 900 & 400 & 200 & - & - & - & - & - & - & 200 & - \\
\hline & & & & Acti & & & & & & & & & \\
\hline Gourie-Devi et al (Bangalore India) $)^{23}$ & - & 967 & 150 & 883 & 76 & - & - & - & - & - & - & - & - \\
\hline Benamer (Libya) ${ }^{24}$ & - & - & - & 190 & 60 & - & - & - & - & - & - & 5.9 & - \\
\hline Quet et al (rural Mexican community)' & - & - & 290 & 390 & 170 & - & - & 30 & - & - & - & - & - \\
\hline Kandil et al (Assiut, Egypt) ${ }^{22}$ & - & - & - & - & - & - & 26 & - & - & 62 & 12 & - & - \\
\hline
\end{tabular}

Note: - means disorders not included in the study.

Abbreviations: D, dementia; M, migraine; S, stroke; E, epilepsy; P, Parkinson's disease; CP, cerebral palsy; DY, dystonia; CA, cerebellar ataxia; TN, trigeminal neuralgia; C, chorea; A, athetosis; MS, multiple sclerosis; SCD, spinal cord disorders.

In the Al Kharga district, the order of frequency of prevalence of the neurological disorders studied was as follows: dementia, epilepsy, stroke, Parkinson's disease, cerebral palsy, cerebellar ataxia, chorea, dystonia, and athetosis. ${ }^{7}$

These variable results of different epidemiological studies might be attributed to differences in the methodology and types of neurological disorders studied; the impact of different environmental factors in diverse geographic areas; and different genetic compositions of the studied populations.

The prevalence of multiple sclerosis $(13.7 / 100,000)$ and spinal cord disorders $(63 / 100,000)(18 / 100,000$ traumatic and 45/100,000 nontraumatic causes) in Al Quseir City are the first results of a community-based epidemiological study in Egypt.

While Radhakrishnan et al recorded a lower prevalence of multiple sclerosis in Libya $(5.9 / 100,000)^{20}$ than that recorded in our study, MacDonald et al recorded a much higher prevalence $(200 / 100,000)$ in the UK. ${ }^{9}$ On the other hand, an intermediate figure $(33.9 / 100,000)$ for the prevalence of multiple sclerosis was recorded by Çelik et al in the metropolitan area of Edrine City, Turkey. ${ }^{21}$ This wide variation in the prevalence of multiple sclerosis worldwide could be attributed to differences in climate, race, immigration, and emigration, as well as varied genetic predispositions of the studied sample frame.

This study clarified important issues regarding the epidemiology of the studied neurological disorders, which can be summarized as follows:

1. The high prevalence of Parkinson's disease $(452.1 / 100,000)$ in comparison with worldwide studies and those in other localities in Egypt, which could be attributed to environmental pollution by heavy metals (manganese, lead, and phosphorus) in this area.

2. The higher prevalence of cerebral palsy (3.6/1000) than in worldwide records and previously recorded data in Al Kharga District, Egypt could be explained by a lack of antenatal, perinatal, and postnatal care in Al-Quseir City.

3. The lower prevalence of chorea in Al-Quseir City $(21.03 / 100,000)$ in comparison to the other two studies conducted in our country (A1 Kharga district: 31.96/100,000; ${ }^{7}$ Assiut: $62.00 / 100,000^{22}$ ) for rheumatic chorea could be attributed to governmental efforts for the eradication of rheumatic activities in the last few years.

Epidemiological studies represent a faithful mirror that reflects the burden of neurological disorders worldwide. Door-to-door surveys, with direct personal interviews with both health-seeking and non-health-seeking individuals, gives a better chance for diagnosing rare neurological disorders. It remains the gold standard method of epidemiological studies, especially in the absence of existing coded data due to a lack of medical registry systems and health insurance coverage.

\section{Conclusion}

1. This study had the aim of evaluating the prevalence of trigeminal neuralgia, multiple sclerosis, and spinal cord disorders for the first time in Egypt.

2. The study shows a high prevalence of Parkinson's disease, cerebral palsy, and stroke in Al Quseir City compared with other cities worldwide.

3. The study shows a marked decline in the prevalence of chorea in Egypt, compared to a previous study. ${ }^{22}$

\section{Disclosure}

The authors report no conflicts of interest in this work.

\section{References}

1. Quet F, Odermatt P, Preux PM. Challenges of epidemiological research on epilepsy in resource-poor countries. Neuroepidemiology. 2008;30(1):3-5. 
2. Gaber SM, Aly SM, Masood KA. [Center of Information and DecisionMaking, Red Sea Governorate Achievement Index]. Secretary General of Red Sea Governorate; 2010. Arabic.

3. El Tallawy HN, Farghaly WM, Metwaly NA, et al. Door-to-door survey of major neurological disorders in Al Kharga District, New Valley, Egypt: methodological aspects. Neuroepidemiology. 2010;35(3):185-190.

4. Bharucha NE, Bharucha EP, Dastur HD, Schoenberg BS. Pilot survey of the prevalence of neurologic disorders in the Parsi community of Bombay. Am J Prev Med. 1987;3(5):293-299.

5. Das SK, Sanyal K. Neuroepidemiology of major neurological disorders in rural Bengal. Neurol India. 1996;44(2):47-58.

6. Abramson JH. Cross-sectional studies. In: Detels R, Holland WW, McEwan J, Omenn GS, editors. Oxford Textbook of Public Health New York: Oxford University Press; 1997:517-535.

7. El Tallawy HN, Farghaly WM, Rageh TA, et al. Epidemiology of major neurological disorders project in Al Kharga district, New Valley, Egypt. Neuroepidemiology. 2010;35(4):291-297.

8. Casetta I, Faggioli R, Cesnik E, et al. Incidence of childhood and adolescence epilepsy in Ferrara, Italy, 1995-2005 [abstract]. 13th National Meeting of Italian Neuroepidemiology Association; Verona, Italy; 2008. Neuroepidemiology. 2008;31:203.

9. MacDonald BK, Cockerell OC, Sander JW, Shorvon SD. The incidence and lifetime prevalence of neurological disorders in a prospective community-based study in the UK. Brain. 2000;123(Pt 4): 665-676.

10. Preux PM, Druet-Cabanac M. Epidemiology and aetiology of epilepsy in sub-Saharan Africa. Lancet Neurol. 2005;4(1):21-31.

11. Winkler AS, Kerschbaumsteiner K, Stelzhammer B, Meindl M, Kaaya J, Schmutzhard E. Prevalence, incidence, and clinical characteristics of epilepsy-a community-based door-to-door study in northern Tanzania. Epilepsia. 2009;50(10):2310-2313.

12. Benn EK, Hauser WA, Shih T, et al. Estimating the incidence of first unprovoked seizure and newly diagnosed epilepsy in the low-income urban community of Northern Manhattan, New York City. Epilepsia. 2008;49(8):1431-1439.

13. Kotsopoulos IA, van Merode T, Kessels FG, de Krom MC, Knottnerus JA. Systematic review and meta-analysis of incidence studies of epilepsy and unprovoked seizures. Epilepsia. 2002;43(11):1402-1409.
14. Rothwell PM, Coull AJ, Silver LE, et al. Population-based study of event-rate, incidence, case fatality, and mortality for all acute vascular events in all arterial territories (Oxford Vascular Study). Lancet. 2005;366(9499):1773-1783.

15. Kandil MR, Ahmed HN, Farwez H. Incidence and prevalence of nonfatal cerebro-vascular stroke and TIA in Upper Epypt (Sohag). Egypt J Neurol Psychiatry Neurosurg. 1996;33:37-44.

16. Bleicher JN, Hamiel S, Gengler JS, Antimarino J. A survey of facial paralysis: etiology and incidence. Ear Nose Throat J. 1996;75(6): 355-358.

17. Savettieri G, Salemi G, Rocca WA, et al. Incidence and lifetime prevalence of Bell's palsy in two Sicilian municipalities. Sicilian Neuro-Epidemiologic Study (SNES) Group. Acta Neurol Scand. 1996; 94(1):71-75.

18. Rowlands S, Hooper R, Hughes R, Burney P. The epidemiology and treatment of Bell's palsy in the UK. Eur J Neurol. 2002;9(1):63-67.

19. Quet F, Preux PM, Huerta M, et al. Determining the burden of neurological disorders in populations living in tropical areas: who would be questioned? Lessons from a Mexican rural community. Neuroepidemiology. 2011;36(3):194-203.

20. Radhakrishnan K, Ashok PP, Sridharan R, Mousa ME. Prevalence and pattern of multiple sclerosis in Benghazi, north-eastern Libya. J Neurol Sci. 1985;70(1):39-46.

21. Çelik Y, Birgili Ö, Kiyat A, et al. Prevalence of Multiple Sclerosis in the Metropolitan Area of Edirne City, Turkey. Balkan Med J. 2011;28(2):193-196.

22. Kandil MR, Tohamy SA, Fattah MA, Ahmed HN, Farwiez HM. Prevalence of chorea, dyatonia and athetosis in Assiut, Egypt: a clinical and epidemiological study. Neuroepidemiology. 1994;13(5):202-210.

23. Gourie-Devi M, Gururai G, Satishchandra P, Subbarkrishna DK. Prevalence of neurological disorders in Bangalore, India: a community-based study with a comparison between urban and rural areas. Neuroepidemiology. 2004;23(6):261-268.

24. Benamer HT. Neurological disorders in Libya: an overview. Neuroepidemiology. 2007;29(3-4):143-149.
Neuropsychiatric Disease and Treatment

\section{Publish your work in this journal}

Neuropsychiatric Disease and Treatment is an international, peerreviewed journal of clinical therapeutics and pharmacology focusing on concise rapid reporting of clinical or pre-clinical studies on a range of neuropsychiatric and neurological disorders. This journal is indexed on PubMed Central, the 'PsycINFO' database and CAS

\section{Dovepress}

The manuscript management system is completely online and includes a very quick and fair peer-review system, which is all easy to use. Visit http://www.dovepress.com/testimonials.php to read real quotes from published authors. 